\title{
Review
}

\section{Oxygen devices and delivery systems}

Cite as: Hardavella G, Karampinis I, Frille A, et al. Oxygen devices and delivery systems. Breathe 2019; 15: e108-e116.

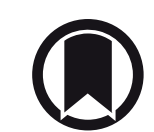

\section{CrossMark}

(C)ERS 2019

Oxygen use has extended from inpatient to outpatient settings for patients with chronic pulmonary diseases and complications of hypoxaemia. This article presents an overview of oxygen devices (oxygen concentrators, compressed gas cylinders and liquid oxygen) and delivery systems (high- and low-flow). The indications, advantages and disadvantages of each device and delivery system are presented, aiming to offer updated knowledge to the multidisciplinary team members managing patients with respiratory failure, and therefore allowing appropriate selection of devices and delivery systems that are tailored to the needs of each patient.

\section{Introduction}

Oxygen use has extended from inpatient to outpatient settings for patients with chronic pulmonary diseases and complications of hypoxaemia. The Nocturnal Oxygen Trial and a study published by the British Medical Research Council are the landmark studies that have consolidated evidence for domiciliary oxygen use $[1,2]$. The following three groups of patients with chronic hypoxaemic lung diseases are suitable for longterm oxygen therapy (LTOT) [3, 4]:

1) Patients with arterial oxygen tension $\left(\mathrm{PaO}_{2}\right)$ $\leq 55 \mathrm{mmHg}$ at rest in nonrecumbent position, despite optimal treatment of underlying condition.

2) Patients with $\mathrm{PaO}_{2}>55 \mathrm{mmHg}$ associated with evidence of central nervous system dysfunction, cor pulmonale, secondary pulmonary hypertension or polycythaemia.
3) Patients with demonstrable fall in $\mathrm{PaO}_{2}$ below $55 \mathrm{mmHg}$ and desaturation during sleep and/ or exercise.

Nowadays, LTOT use is higher in women, and this is projected to increase further in the near future due to the high number of middle-aged female smokers [5]. There is a large variety of available oxygen-conserving devices and, considering the high costs of LTOT and the impact on patients' healthrelated quality of life, optimal device selection and prescribing requires a clear understanding of these devices [3, 6-8]. In this review, we will present different oxygen devices and delivery systems.

\section{Oxygen concentrators}

\section{How do they work?}

Oxygen concentrators provide a safe source of oxygen-enriched air. Oxygen concentrators 
(sometimes referred to as oxygen generators) are devices that draw room air through a series of filters that remove dust, bacteria and other particulates. In the first step of the concentration process, the machine forces air into one of the two cylinders containing a molecular "sieve" material or semipermeable membranes, where nitrogen is absorbed, leaving concentrated oxygen ( $90 \%$ or higher) and a small percentage of other gases found in room air. At the same time, in the other cylinder, nitrogen is desorbed and drawn out into the atmosphere. In the second step, the function of the cylinders is reversed in a timed cycle, providing a continuous flow of oxygen to the patient. A typical oxygen concentrator may deliver oxygen flows of $0.5-5 \mathrm{~L} \cdot \mathrm{min}^{-1}$ (lowflow oxygen concentrators), while some models may generate up to $10 \mathrm{~L} \cdot \mathrm{min}^{-1}$ (high-flow oxygen concentrators) $[9,10]$.

\section{Types of oxygen concentrators and oxygen delivery}

There are two types of oxygen concentrators: stationary and portable [9, 10]. Stationary (home) concentrators provide an uninterrupted oxygen supply with a flow ranging from 0.5 to 10-15 L·min ${ }^{-1}$. They have a mean weight of about $10 \mathrm{~kg}$. They have several ergonomic handles built in, to offer options for lifting or rolling the device (figure 1a). New miniature concentrators have recently entered the market, making stationary concentrators more mobile than ever. The concentrator plugs into the main electricity supply at home, using $300 \mathrm{~W}$ (or below) per hour (about the same as four light bulbs). A back-up compressed gas cylinder is sometimes provided, to use in case of a power failure.

A relatively new option is a super small home concentrator, which can weigh approximately $4.5 \mathrm{~kg}$. These units run on both alternating current (AC; e.g. from a wall socket) and direct current (DC; e.g. from a cigarette lighter socket) and are mobile (e.g. they can be easily moved from one room to the other or they can be transported by car for travel). They currently support oxygen flow rates up to $2 \mathrm{~L} \cdot \mathrm{min}^{-1}$.

Portable oxygen concentrators are the latest technology for LTOT users who desire a small, lightweight and portable oxygen solution in a compact and mobile unit (figure 1b). Portable concentrators vary in weight, size, oxygen flow settings, range of $\mathrm{L} \cdot \mathrm{min}^{-1}$ and battery life, as well as other specifications.

The key differences between stationary and portable concentrators can be summarised by four major factors: 1) oxygen output, 2) size and weight, 3) power options and 4) price. Stationary oxygen concentrators have higher oxygen output and lower costs. Portable oxygen concentrators offer smaller size and less weight as well as greater flexibility with power sources. For patients who live active lives and are often away from an AC (wall socket) power source, a portable oxygen concentrator is the best choice $[9,10]$. Most portable oxygen concentrators use lithium ion batteries, which degrade over time. Most of these batteries can be recharged approximately 300 times without significant degradation.

Generally, there are two types of oxygen delivery in oxygen concentrators: continuous flow dose delivery and pulse mode delivery. Continuous flow dose delivery supplies a constant, steady and reliable oxygen flow based on the setting number in $\mathrm{L} \cdot \mathrm{min}^{-1}$, while pulse mode delivery delivers a pulsed "bolus" of oxygen when the user begins to take a breath. Initially, the individual flow setting should be adjusted.

\section{Indications}

Stationary oxygen concentrators are commonly used by patients on LTOT, as they are cost-effective and are safer than using compressed gas cylinders. Oxygen concentrators are recommended for patients using oxygen for $>1.4 \mathrm{~h} \cdot \mathrm{day}^{-1}$ [10]. Guidelines do not give indications for the choice of the delivery device but only suggest the use of a portable device in subjects on LTOT who regularly go outside [9]. Portable oxygen concentrators for ambulatory oxygen therapy are offered to people already on LTOT who want to use oxygen outside the home. Ambulatory oxygen therapy can improve exercise tolerance and breathlessness, although there is no benefit from oxygen before and after exercise in most patients with chronic obstructive pulmonary disease (COPD). Furthermore, ambulatory oxygen therapy may allow increased daily oxygen use and/or better compliance.

\section{Advantages and disadvantages}

Evidence arising from both prospective and retrospective trials and randomised controlled trials (with a minimum 12-month follow-up) suggests that oxygen concentrator use where appropriate improves
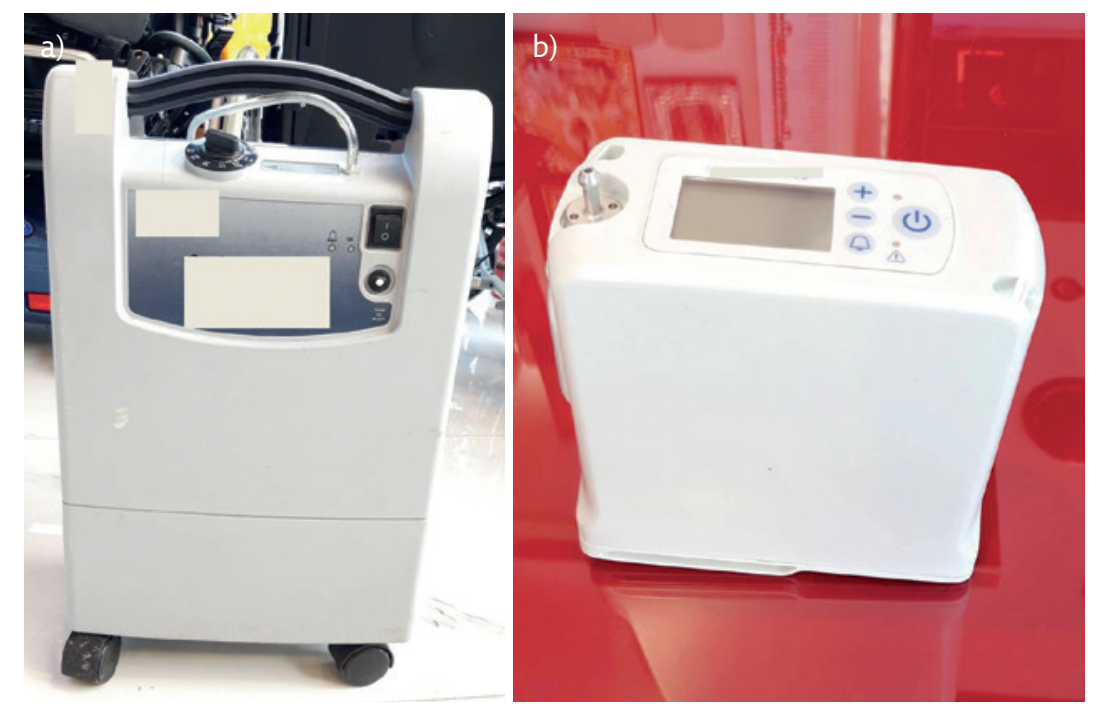

Figure 1 a) Stationary oxygen concentrator. b) Portable oxygen concentrator. 
survival rates for respiratory conditions, improves mental attentiveness, increases stamina and improves mood. The majority of studies have been performed in patients with COPD and it is of note that the duration of oxygen supply per se affects survival. In hypoxaemic chronic obstructive lung disease, continuous oxygen therapy is associated with a lower mortality than is nocturnal oxygen therapy [1-5].

\section{Advantages}

Oxygen concentrators do not need to be refilled. The concentrators run on electrical power and thus supply an unlimited amount of oxygen. Portable concentrators can be used in an "on-the-go" mode with a battery pack, resulting in up to $12 \mathrm{~h}$ of continuous use for some models. From a longterm view, concentrators are more cost-effective than compressed gas cylinders, and they are known to last for up to $1500 \mathrm{~h}$ of continuous use $[11,12]$.

\section{Disadvantages}

The significant disadvantage of oxygen concentrators is the need for electrical power to function. It is necessary to prepare for unscheduled power outages by setting up a backup power generator at home. Patients using stationary oxygen concentrators need to consider changing filters weekly, regular servicing and the warm-up period of the machine, as well as noise and vibration from the older models of device $[11,12]$.

\section{Related costs}

The global market for medical oxygen concentrators was valued at USD 1.75 billion in 2018 [13]. The market is anticipated to expand at a compound annual growth rate of $7.4 \%$ between 2019 and 2025 [13]. The prices of new home oxygen concentrators depend on batteries and other accessories, and range from USD 595 to USD 2000. Used oxygen concentrators are cheaper (USD 595-1500), depending on the hours, warranty, and condition of the unit. However, the rental of a stationary oxygen concentrator can run from USD 35 per day to over USD 200 per week, but extended rental contracts may allow for a discount [13].

\section{Compressed gas cylinders}

Compressed gas cylinders have certain differences when compared to oxygen concentrators, and these are summarised in table 1. Figure 2 a shows a compressed gas cylinder and figure $2 \mathrm{~b}$ shows a patient in bed receiving oxygen from it via a nasal cannula.

\section{Properties, classification and appearance}

A cylinder is a metal container filled with compressed gas and held under high pressure. Oxygen cylinders are available in a range of sizes that determine the capacity for oxygen. For compressed oxygen cylinders, there are three methods of delivering portable oxygen: a portable cylinder, lightweight cylinder, and home fill cylinder [14]. When fully filled with oxygen, cylinders range from small portable cylinders for ambulatory use $(e . g .53 \mathrm{~cm}$ height, $3 \mathrm{~kg}$ weight, $430 \mathrm{~L}$ of oxygen) to large static cylinders (e.g. $71 \mathrm{~cm}$ height, $18 \mathrm{~kg}$ weight, $2122 \mathrm{~L}$ of oxygen) [14]. A backpack, trolley or wheeled cart may be necessary for locomotion, depending on cylinder size and weight as well as the patient's activity and fitness level. The oxygen cylinders are colour coded with a white body to distinguish them from other medical gases.

\section{How do they work?}

A regulator is attached to the cylinder's top and works like a tap, allowing the safe adjustment

Table 1 Differences between oxygen concentrators and compressed gas cylinders

\begin{tabular}{|c|c|c|}
\hline & Oxygen concentrators & Compressed oxygen cylinders \\
\hline $\begin{array}{l}\text { Power source } \\
\text { required }\end{array}$ & $\begin{array}{l}\text { Yes, continuously (according to model: } \\
100-600 \mathrm{~W} \text { ) }\end{array}$ & No \\
\hline Transport required & Only at the time of installation & Yes, regularly; heavy and costly to transport \\
\hline $\begin{array}{l}\text { Exhaustible oxygen } \\
\text { supply }\end{array}$ & $\begin{array}{l}\text { No, continuous supply as long as power remains } \\
\text { uninterrupted }\end{array}$ & $\begin{array}{l}\text { Yes, depending on the size, storage pressure, and } \\
\text { patient needs }\end{array}$ \\
\hline User care & $\begin{array}{l}\text { Moderate: cleaning of filters and device exterior, } \\
\text { and minimise fire hazard }\end{array}$ & $\begin{array}{l}\text { Minimal: regular checking, minimise fire hazard } \\
\text { (no grease or flammables) }\end{array}$ \\
\hline Operational costs & Small: electricity and maintenance & $\begin{array}{l}\text { High: cylinder refills and transport from refilling } \\
\text { station to a hospital }\end{array}$ \\
\hline Maintenance & $\begin{array}{l}\text { Moderate: check for low oxygen output with } \\
\text { analyser }\end{array}$ & Moderate: check for pressure leaks with gauge \\
\hline
\end{tabular}


of oxygen flow rate provided, in $L \cdot \mathrm{min}^{-1}$. When the tap is manually opened, the oxygen takes the line of least resistance to the patient via an oxygen delivery device (e.g. tube with a mask or nasal cannula). A pressure reading (barometer) displays the remaining oxygen pressure in the cylinder, to estimate the amount of oxygen available for supply.

The capacity of a compressed oxygen cylinder is comparatively low: e.g. with 200 bar filling pressure and $400 \mathrm{~L}$ of oxygen, the patient's oxygen supply will suffice for $2.5 \mathrm{~h}$, depending on flow rate [15].

At home or in the hospital, cylinders are changed by the gas provider. The frequency of deliveries depends on the cylinder's size and oxygen consumption. Home fill cylinders can be refilled by an oxygen concentrator [14].

Compared to continuous oxygen flow, oxygenconserving devices deliver pulsed oxygen during inspiration only, triggered by the patient's inspiration. These "demand" oxygen delivery systems enable cylinders to last longer, since the oxygen waste during expiration is reduced. It has been shown that conservers can reduce oxygen usage by $50 \%$, leading to a reduced number of home deliveries and thus lower costs $[14,15]$. However, oxygenconserving devices vary in their ability to maintain arterial oxygen saturation levels during exercise, and some patients struggle to trigger them due to the advanced stage of their lung disease [14].

\section{Indications}

For patients requiring supplemental oxygen at home, compressed gas cylinders are commonly combined with an oxygen concentrator. These patients are less mobile, spend the majority of time at home and are rarely in need of mobile oxygen, which is why compressed gas cylinders may serve as a back-up if a power cut or concentrator failure occurs [14, 15].

In hospital, mobile compressed gas cylinders find their main use as a temporary oxygen supply for invasively ventilated patients when they need to undergo diagnostic or therapeutic procedures outside the intensive care unit $[14,15]$.

\section{Correlation with clinical outcomes}

When standard portable cylinders were compared with lightweight cylinders in patients with COPD, in a prospective, randomised, clinical, multicentre trial conducted by the COPD Clinical Research Network, no differences were found in activity levels, oxygen saturation, Borg score or 6-min walk test [16].

$A$ randomised multi-arm repeated-measures prospective study compared the use of liquid oxygen, home fill cylinder, portable concentrator and lightweight cylinder in 39 patients with stable severe COPD. There were no differences
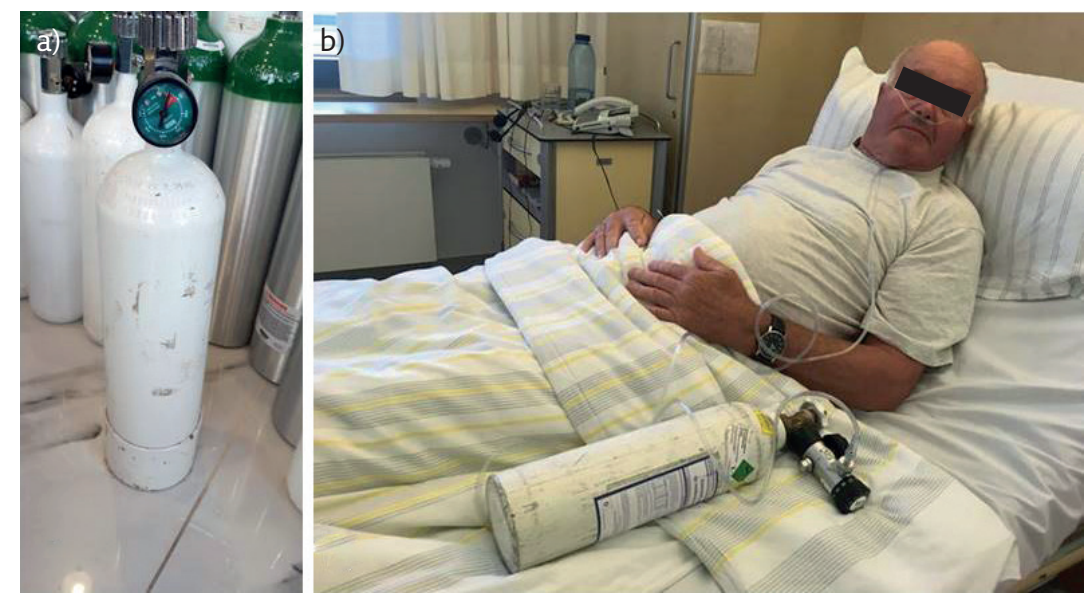

Figure 2 a) Compressed gas cylinder with an attached flowmeter, and b) a patient receiving oxygen from this device.

between oxygen saturation, distance walked, or time used [14, 17]. Another prospective, randomised clinical study performed in COPD patients compared liquid oxygen and cylinders for domiciliary portable use and found that neither of them improved the quality of life [18].

\section{Advantages and disadvantages}

Advantages

Nowadays, compressed oxygen cylinders are comparatively the least convenient oxygen supply modality. However, depending on the demand of the patient, a cylinder may suffice in combination with a stationary oxygen concentrator [14].

\section{Disadvantages}

Due to their size and weight, cylinders are less convenient to carry without equipment. Patients can benefit from the provision of trolleys, wheeled carts or backpacks to enable them to carry home oxygen equipment [14]. When compared to liquid oxygen, cylinders were least favoured, while liquid oxygen was most favoured, with the lowest long-term costs $[14,15]$. Despite the lack of improvement in the quality of life, patients using portable cylinders, in comparison with liquid oxygen, spent significantly shorter periods outside the house and used their oxygen less [18].

\section{Case presentation}

A 90-year-old female patient from a nursing home presented at the emergency department due to acute onset of shortness of breath, cough and purulent sputum for the past few days. She denied fever and night sweats. She reported that she is a heavy smoker (80 pack-years of cigarettes) and has not been leaving the bed lately due to the deterioration of her COPD. So far, she had not 
been in need of supplementary oxygen. Initial arterial blood gas testing showed hypoxaemia $\left(\mathrm{PaO}_{2}\right.$ $50 \mathrm{mmHg})$ without hypercapnia $\left(\mathrm{PaCO}_{2} 40 \mathrm{mmHg}\right)$ and with normal $\mathrm{pH}$ (7.40). Chest radiography was unremarkable except for signs of bilateral apical emphysema.

She was admitted for an acute exacerbation of COPD. After treatment with bronchodilators, intravenous corticosteroids, antibiotics, and oxygen via nasal cannula, she recovered quickly, within 5 days. Only the hypoxaemia did not improve back to normal limits without nasal oxygen supply. Since $2 \mathrm{~L} \cdot \mathrm{min}^{-1}$ nasal oxygen fully resolved hypoxaemia $\left(\mathrm{PaO}_{2} 70 \mathrm{mmHg}\right)$ without developing hypercapnia, she was prescribed nasal oxygen supply.

After exhaustive discussion with her about her present needs at the nursing home, we decided to prescribe her an oxygen concentrator in combination with a compressed oxygen cylinder. With the help of the oxygen concentrator she would be supplied with oxygen in her room. The compressed oxygen cylinder would supply her with mobile oxygen when she needed to leave her room (e.g. when her family members visit her or she has a medical appointment outside the premises).

\section{Liquid oxygen}

The introduction of liquid oxygen transformed the landscape of domiciliary oxygen therapy [12]. The first home-based liquid oxygen system was developed in 1965 with the view of providing a larger stationary oxygen system inside the home, with smaller liquid oxygen portables that can be refilled and used outside the home $[19,20]$.

\section{How do liquid oxygen systems deliver oxygen?}

Liquid oxygen is a cryogenic liquid, that is, a liquefied gas with a boiling point of $-183^{\circ} \mathrm{C}[21-23]$. Liquid oxygen allows a larger quantity of oxygen (gas) to be stored as a liquid in a small receptacle [24]. The 860:1 expansion ratio for liquid oxygen means that when $1 \mathrm{~L}$ of liquid oxygen is evaporated, it expands to approximately $860 \mathrm{~L}$ of gaseous oxygen [25]. The medical liquid oxygen (minimum $99.5 \%$ purity) must first be vaporised to a compressed gas then warmed at ambient (room) temperature inside the equipment before the patient can receive the oxygen through tubing into the nostrils via a nasal cannula [22]. How long a patient can use the ambulatory oxygen in the portable flask depends on the flow rate of oxygen the patient is using, as prescribed by the treating physician [21].

Both the stationary storage containers ("mother unit vessels") and portables come in different sizes. These cryogenic containers keep the liquid cold [24]. Small stationary containers may provide a convenient refill supply in a car or van during extended trips from home [25]. If the patient is on high-flow liquid oxygen (up to $15 \mathrm{~L} \cdot \mathrm{min}^{-1}$ of continuous flow oxygen), it is important to note that ice may form on the portable's heat exchange coils due to freezing of ambient humidity [25]. These patients usually possess two portable systems to facilitate continuous usage, allowing for de-icing of one of the units while using the ambulatory oxygen in the other [25].

\section{Indications}

Selecting the right oxygen delivery system for the right candidate can be challenging for the clinician. There are two major deciding factors when choosing between liquid oxygen and oxygen from a compressed gas cylinder, which are convenience and efficiency. For ambulatory patients who wish to be mobile, limited French data from the ANTADIR registry support the use of portable liquid oxygen in this group [26]. According to the literature, liquid oxygen may be suitable for patients with chronic respiratory disabilities who could return to work, require flow rates $>5 \mathrm{~L} \cdot \mathrm{min}^{-1}$, can walk, and cannot carry out their activities without an oxygen supply $[12,18]$. For ambulatory patients requiring highflow oxygen, liquid oxygen is the most practical option [25]. Figure 3 shows a patient with a nasal cannula and liquid oxygen tank.

\section{Correlation with clinical outcomes}

Patients using liquid oxygen are more apt to venture outside the home and use daily oxygen for longer periods compared with their counterparts using

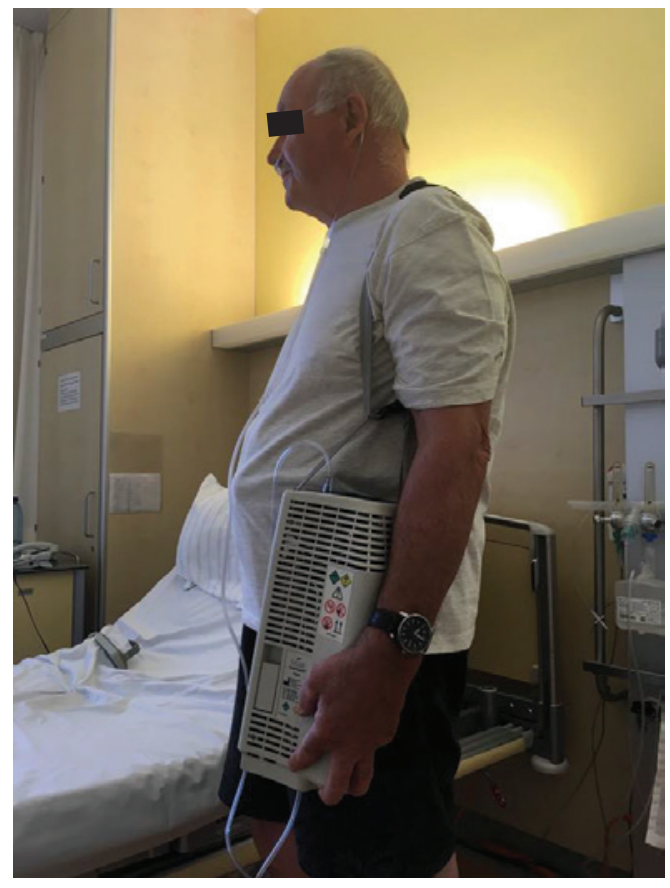

Figure 3 Patient with a nasal cannula and liquid oxygen tank. 
oxygen concentrators [27]. In addition, liquid oxygen therapy improves both patient compliance and health-related quality of life [18, 28]. Significant differences, favouring liquid oxygen therapy versus oxygen concentrators, have been found in the following quality of life measures: physical function, body care, ambulation, social interaction and total Sickness Impact Profile score [28].

\section{Advantages and disadvantages}

Advantages

Liquid oxygen takes up less space than oxygen in its gas form, making it easier and lighter to carry around. Liquid oxygen tanks are safer compared to compressed gas cylinders because they are under lower pressure. Of the three current modes of delivery for domiciliary oxygen treatment, the most flexible and convenient source of home oxygen is the liquid oxygen system [29]. Light portable containers are refilled with liquid oxygen from the large stationary reservoir at the patient's home whenever necessary, giving the patient control over the refilling frequency $[25,30]$. The base equipment provides oxygen for $>11$ days, and ambulatory oxygen in the portable canisters lasts $8-10 \mathrm{~h}[28,31]$. At a flow rate of $2 \mathrm{~L} \cdot \mathrm{min}^{-1}$ of oxygen, this longer duration of oxygen supply in liquid form benefits patients with chronic respiratory disease who would otherwise be restricted to a maximum of $2 \mathrm{~h}$ of oxygen, thus limiting their time spent outdoors [18]. Modern liquid oxygen canisters are less cumbersome for the patient to carry than previously reported [32]: $3.5 \mathrm{~kg}$ when full versus $2.5 \mathrm{~kg}$ when empty [18] for the larger portable canisters, and even lighter for the smaller ones. When compared to gaseous oxygen, patients prefer the liquid oxygen system because the oxygen lasts longer, filling the canister is simpler, and the portable system is easier to carry due to a lighter weight [18]. However, portable oxygen concentrators are even lighter than liquid oxygen canisters because they do not require a storage reservoir of pressurised oxygen. Nonetheless, oxygen concentrators are less convenient for patients than liquid oxygen because they require internal batteries, automobile adaptors or standard electricity, and this need for a continuous power source could hinder patient mobility and independence.

\section{Disadvantages}

Oxygen tanks and liquid oxygen canisters are limited by a finite capacity defined by their size, whereas portable oxygen concentrators have no compressed tanks to exchange or refill given that they draw in ambient air directly from the surroundings, filter it instantly and deliver the approximately $93 \%$ pure oxygen directly to the patient through the nasal cannula. It is necessary to keep the large liquid oxygen containers filled at home to replenish the smaller, portable tanks frequently. The recurring oxygen deliveries can get quite expensive. Another important point to remember is that the liquid oxygen constantly evaporates and needs to be used and resupplied by a professional service provider at least two to three times a month. Therefore, one of the main drawbacks for liquid oxygen therapy is the cost. In addition, the number of patients with impaired lung function wishing to travel by aeroplane is increasing, but aviation regulations prohibit liquid oxygen on commercial aircraft [33].

\section{Cost}

Compared with oxygen concentrator treatment, long-term liquid oxygen therapy is about four times more expensive [28, 30]. In their Swedish study in 1998, ANDERSSON et al. [28] found that the average total cost per patient over a 6 -month period was USD 1310 for the concentrator group versus USD 4950 for the liquid oxygen group. There is a high delivery/service cost associated with refilling the liquid oxygen stationary systems at a set frequency, contingent on the oxygen flow setting and the unit's size [25]. In addition, other associated costs include electricity, acquisition costs and metering gas to the patient [25].

\section{Oxygen delivery systems}

Oxygen delivery systems are categorised into lowflow and high-flow systems. Low-flow systems provide lower oxygen flow than the actual inspiratory flow $\left(\sim 30 \mathrm{~L} \cdot \mathrm{min}^{-1}\right)$. When the patient inspires, the oxygen is diluted with room air, and the degree of dilution depends on the inspiratory flows. Therefore, these oxygen delivery systems do not allow for accurate calculation of the inspiratory oxygen fraction $\left(\mathrm{F}_{\mathrm{I}}\right)$. High-flow oxygen delivery systems provide higher oxygen flows and the $\mathrm{FIO}_{2}$ is stable and is not affected by the patient's type of breathing.

\section{Low-flow oxygen delivery systems}

\section{Nasal cannula}

A nasal cannula is the most common oxygen delivery system, used for mild hypoxia (figure 4a). It delivers oxygen into the nasopharyngeal space and can be set to deliver between 1 and $6 \mathrm{~L} \cdot \mathrm{min}^{-1}$ (24$40 \% \mathrm{FlO}_{2}$ ) (table 2). $\mathrm{FIO}_{2}$ increases by approximately $4 \%$ with each litre of oxygen per minute. Nasal cannulae are widely used in domiciliary oxygen devices. An oxygen flow $>6 \mathrm{~L} \cdot \mathrm{min}^{-1}$ should be avoided as it can dry the nasal mucosa and can disturb sleeping patterns [34, 35]. A nasal cannula is convenient as the patient can talk and eat while receiving oxygen, and it is easy to use. However, 

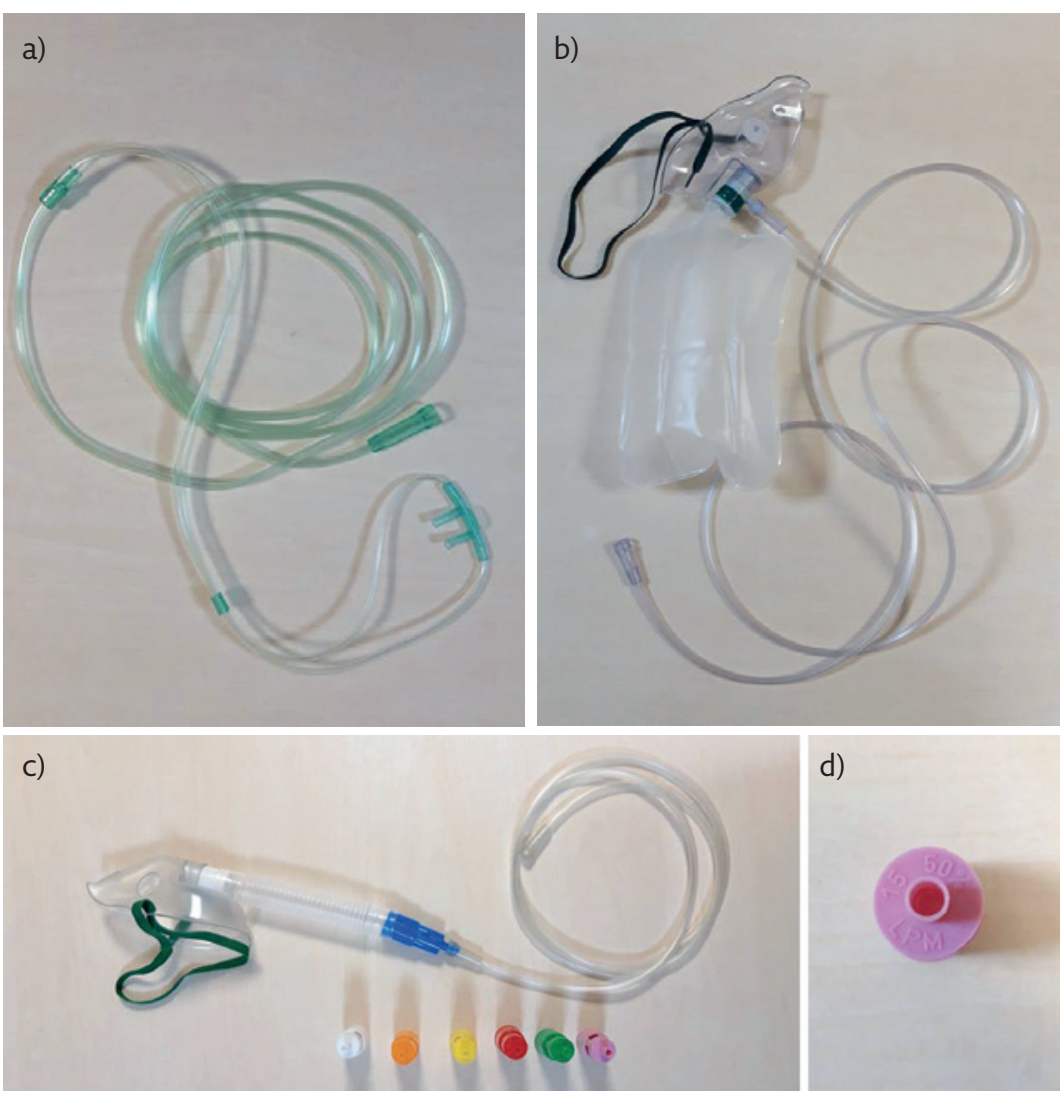

Figure 4 a) Nasal cannula. b) Non-rebreather mask. c) Venturi mask with different sized ports to change the $\mathrm{F}_{2} \mathrm{O}_{2}$ delivered (24-50\%). d) $\mathrm{FIO}_{2}$ and oxygen flow are clearly stated on the bottom of each port.
Non-rebreather mask

A non-rebreather mask is a low-flow device with high $\mathrm{FlO}_{2}$. It uses a reservoir bag $(\sim 1000 \mathrm{~mL})$ to deliver a higher concentration of oxygen (figure $4 \mathrm{~b})$. A one-way valve between the mask and the reservoir bag prevents the patient from inhaling expired air. It can be set to deliver between 10 and $15 \mathrm{~L} \cdot \mathrm{min}^{-1}$ (80-95\% oxygen). Oxygen flow $<10 \mathrm{~L} \cdot \mathrm{min}^{-1}$ can cause the bag to completely collapse during inspiration. $\mathrm{F}_{\mathrm{O}}$ depends on the patient's pattern of breathing. This mask is useful in severely hypoxic patients who are ventilating well, but it carries the risk of carbon dioxide retention and aspiration in case of vomiting [34, 35].

\section{Transtracheal oxygen catheter}

Transtracheal oxygen catheters (TTOCs) can be effective in palliating breathlessness and hypoxaemia. The TTOC delivers oxygen directly into the trachea and it is inserted percutaneously into the trachea using Seldinger technique. However, TTOC placement has not gained widespread popularity as only a few physicians are trained to insert the TTOC or manage patients with it, and there is also a widespread reservation towards performing this invasive procedure on hypoxaemic, elderly, frail patients [36].

Oxygen flow through a $T \mathrm{CC}$ ranges between 0.5 and $4 \mathrm{~L} \cdot \mathrm{min}^{-1}$. Oxygen delivery by $\Pi \mathrm{TOC}$ bypasses the anatomical "dead space" in the upper airways and mouth, allowing oxygen to pass directly into the trachea. This reduces the overall oxygen needed during rest and with exercise.

\section{cannulae}

\begin{tabular}{lc}
\hline $\mathbf{F}_{\mathrm{IO}_{\mathbf{2}}} \%$ & Flow L· $\mathbf{m i n}^{-\mathbf{1}}$ \\
\hline $24-28$ & $1-2$ \\
$30-35$ & $3-4$ \\
$38-44$ & $5-6$ \\
\hline
\end{tabular}

it can be easily dislodged and is not as effective in patients with deviated septum or polyps.

\section{Simple face mask}

A simple face mask can be set to deliver between 5 and $10 \mathrm{~L} \cdot \mathrm{min}^{-1}\left(35-55 \% \mathrm{FIO}_{2}\right)$ and is indicated when a moderate amount of oxygen is needed. It fits over the patient's mouth and nose, and has side exhalation ports through which the patient exhales carbon dioxide. Humidified air may be added if the oxygen concentrations are causing nasal mucosa dryness. The mask's efficiency relies on how well it fits. Eating and drinking can be difficult with the mask on and it can be confining for some patients, who may feel claustrophobic with the mask on [34, 35].

\section{High-flow oxygen delivery systems}

Rebreather mask

Unlike the non-rebreather mask, there is no oneway valve between the rebreather mask and the reservoir bag and the inspired oxygen and expired air are collected in the reservoir bag.

\section{Venturi mask}

A Venturi mask is a high-flow device that allows precise measurement of $\mathrm{FIO}_{2}$ delivered. It consists of a bottle of sterile water, corrugated tubing, air/ oxygen ratio nebuliser system, a drainage bag, and a mask (e.g. aerosol face mask, tracheostomy mask, T-piece, a face tent). The oxygen flow exceeds the patient's peak expiratory flow. Therefore, it is unlikely for the patient to breathe in air from the room. A Venturi mask utilises different sized ports to change the $\mathrm{FIO}_{2}$ delivered (24-50\%) (figure 4c). The $\mathrm{FIO}_{2}$ and oxygen flow are clearly stated on the bottom of each port (figure 4d). It does not dry mucous membranes, but it is confining for some patients, and it interferes with talking and eating. It is particularly useful in COPD patients, where precise oxygen delivery is crucial [34, 35]. 


\section{High-flow nasal cannula}

A high-flow nasal cannula consists of a flow generator, an air-oxygen blender, a humidifier and a nasal cannula. The flow generator can provide gas flow up to $60 \mathrm{~L} \cdot \mathrm{min}^{-1}$, and the blender escalates $\mathrm{FIO}_{2}$ up to $100 \%$ while the humidifier saturates the gas mixture (at $31-37^{\circ} \mathrm{C}$ ). The heated humidified oxygen is delivered to a wide-bore nasal prong. The flow rate and $\mathrm{FiO}_{2}$ can be independently titrated based on the patient's flow and $\mathrm{F}_{\mathrm{IO}_{2}}$ requirements. Overall, high flows and humidification improve functional residual capacity and mucociliary clearance of secretions, and thereby they reduce the work of breathing [34, 35].

\section{Conclusions}

Appropriate selection of oxygen devices and delivery systems depends on the degree of hypoxaemia, the existing evidence for the patient's underlying diagnosis and patient preference. Respiratory physicians should have a consolidated knowledge of all devices and systems to devise proper and individualised patient-based plans for oxygen therapy.

\section{Affiliations}

\section{Georgia Hardavella ${ }^{1}$, Ioannis Karampinis ${ }^{2}$, Armin Frille ${ }^{3,4}$, Katherina Sreter ${ }^{5}$, Ilona Rousalova ${ }^{6}$}

110th Dept of Respiratory Medicine, Athens Chest Diseases Hospital "Sotiria”, Athens, Greece. ${ }^{2}$ Dept of Thoracic Surgery, General Hospital "Sismanogleio", Athens, Greece. ${ }^{3}$ Dept of Respiratory Medicine, University of Leipzig, Leipzig, Germany. ${ }^{4}$ Integrated Research and Treatment Center (IFB) Adiposity Diseases, University Medical Center Leipzig, Leipzig, Germany. ${ }^{5}$ The Royal Marsden, NHS Foundation Trust, London, UK. ${ }^{6} 1$ st Dept of Tuberculosis and Respiratory Diseases, General University Hospital and First Faculty of Medicine, Charles University, Prague, Czech Republic.

\section{Acknowledgements}

For this contribution, A. Frille was supported by the Federal Ministry of Education and Research (BMBF), Germany, FKZ $01 E 01501$ (IFB Adiposity Diseases, MetaRot program). The authors would like to thank BETABET company for kindly agreeing for photos to be taken of their merchandise.

\section{Conflict of interest}

None declared.

\section{References}

1. Nocturnal Oxygen Therapy Trial Group. Continuous or nocturnal oxygen therapy in hypoxemic chronic obstructive lung disease: a clinical trial. Ann Intern Med 1980; 93: 391-398.

2. Medical Research Council Working Party. Long term domiciliary oxygen therapy in chronic hypoxic cor pulmonale complicating chronic bronchitis and emphysema. Lancet 1981; 317 : 681-686.

3. O'Driscoll BR, Howard LS, Earis J, et al. BTS guideline for oxygen use in adults in healthcare and emergency settings. Thorax 2017; 72: Suppl. 1, ii1-ii90.

4. Meena M, Dixit R, Kewlani JP, et al. Home-based long-term oxygen therapy and oxygen conservation devices: An updated review. Natl J Physiol Pharm Pharmacol 2015; 4: 267-273.

5. Franklin KA, Gustafson T, Ranstam J, et al. Survival and future need of long-term oxygen therapy for chronic obstructive pulmonary disease - gender differences. Respir Med 2007; 101: 1506-1511.

6. Croxton TL, Bailey WC. Long-term oxygen treatment in chronic obstructive pulmonary disease: recommendations for future research: an NHLBI workshop report. Am J Respir Crit Care Med 2006; 174: 373-378

7. Stoller JK, Panos RJ, Krachman S, et al. Oxygen therapy for patients with COPD: current evidence and the long-term oxygen treatment trial. Chest 2010; 138: 179-187.

8. Neri M, Melani AS, Miorelli AM, et al. Long-term oxygen therapy in chronic respiratory failure: a Multicenter Italian Study on Oxygen Therapy Adherence (MISOTA). Respir Med 2006; 100: 795-806.
9. Melani AS, Sestini P, Rottoli P. Home oxygen therapy: re-thinking the role of devices. Expert Rev Clin Pharmacol 2018; 11: 279-289.

10. Jackson M, Shneerson J. An evaluation of the use of concentrators for domiciliary oxygen supply for less than $8 \mathrm{~h}$ day $^{-1}$. Respir Med 1998; 92: 250-255.

11. Diego Gonzalez EG, Mendez Lanza A, Mosquera Pestana JA. Ruidos y averias: factores determinantes en la aceptacion y comportamiento del concentrador de $\mathrm{O}_{2}$. Proyecto Asturias [Noise and machine failures: determining factors in the acceptance and behavior of $\mathrm{O}_{2}$ concentrator. The Asturias project]. An Med Interna 1996; 13: 430-433.

12. Diaz Lobato S, Garcia Gonzalez JL, Alises SM. The debate on continuous home oxygen therapy. Arch Bronconeumol 2015; 51: 31-37

13. Grand View Research. Medical Oxygen Concentrators Market Size, Share \& Trends Analysis Report By Product (Portable, Stationary), By Application (Non-homecare, Homecare), By Technology (Pulse Dose, Continuous Flow), And Segment Forecasts, 2019-2025. Report ID: 978-1-68038-457-4. www. grandviewresearch.com/industry-analysis/medical-oxygenconcentrators-market Date last updated: April 2019. Date last accessed: 12 April 2019.

14. Hardinge M, Annandale J, Bourne S, et al. British Thoracic Society guidelines for home oxygen use in adults. Thorax 2015; 70: Suppl. 1, i1-i43.

15. Magnussen H, Kirsten AM, Köhler D, et al. Leitlinien zur Langzeit-Sauerstofftherapie. Deutsche Gesellschaft für Pneumologie und Beatmungsmedizin e.V. [Guidelines for 
long-term oxygen therapy. German Society for Pneumology and Respiratory Medicine]. Pneumologie 2008; 62: 748-756.

16. Casaburi R, Porszasz J, Hecht A, et al. Influence of lightweight ambulatory oxygen on oxygen use and activity patterns of COPD patients receiving long-term oxygen therapy. COPD 2012: 9: 3-11.

17. Strickland SL, Hogan TM, Hogan RG, et al. A randomized multi-arm repeated-measures prospective study of several modalities of portable oxygen delivery during assessment of functional exercise capacity. Respir Care 2009; 54: 344-349.

18. Lock SH, Blower G, Prynne M, et al. Comparison of liquid and gaseous oxygen for domiciliary portable use. Thorax 1992 47: 98-100.

19. Petty TL. Historical highlights of long-term oxygen therapy Respir Care 2000; 45: 29-36.

20. Petty TL, Casabury R. Recommendations of the Fifth Oxygen Consensus Conference. Respir Care 2000; 45: 957-961.

21. BOC, NHS. Liquid Oxygen Mother Unit/Portable Flask System: Equipment Guide. Manchester, BOC Healthcare, 2012. www.bochomeoxygen.co.uk/en/images/406735_ Healthcare_Liquid_Systems_Handbook_NHS_View_ tcm1109-179233.pdf

22. BOC. Liquid Medical Oxygen: Essential Safety Information. Medical Gas Data Sheet. Manchester, BOC Healthcare, 2013. www.boconline.co.uk/en/images/medical_liquid_oxygen_ tcm410-55834.pdf

23. Air Products. Liquid Oxygen. Allentown, Air Products and Chemicals Inc., 2015. www.airproducts.com/ /media/ files/pdf/company/safetygram-6.pdf

24. McCoy RW. Liquid oxygen applications from hospital to home. Home Pathways 2005; 14: 32.

25. McCoy RW. Options for home oxygen therapy equipment: storage and metering of oxygen in the home. Respir Care 2013; 58: 65-85
26. Pépin JL, Barjhoux CE, Deschaux C, et al. Long-term oxygen therapy at home. Compliance with medical prescription and effective use of therapy. ANTADIR Working Group on Oxygen Therapy. Association Nationale de Traitement à Domicile des Insuffisants Respiratories. Chest 1996; 109: 1144-1150.

27. Su CL, Lee CN, Chen HC, et al. Comparison of domiciliary oxygen using liquid oxygen and concentrator in northern Taiwan. J Formos Med Assoc 2014; 113: 23-32.

28. Andersson A, Ström K, Brodin H, et al. Domiciliary liquid oxygen versus concentrator treatment in chronic hypoxaemia: a cost-utility analysis. Eur Respir J 1998; 12 : 1284-1289.

29. Gorecka D. Liquid oxygen, is it the gold standard? Chron Respir Dis 2005; 2: 181-182.

30. Kacmarek RM. Delivery systems for long-term oxygen therapy. Respir Care 2000; 45: 84-92.

31. Welch GH, Werinberg DE, Welch WP. The use of Medicare home health care services. N Engl J Med 1996; 335: 324-329.

32. Leggett RJ, Flenley DC. Portable oxygen and exercise tolerance in patients with chronic hypoxic cor pulmonale. Br Med J 1977; 2: 84-86

33. Fischer R, Wanka ER, Einhaeupl F, et al. Comparison of portable oxygen concentrators in a simulated airplane environment. Respir Med 2013; 107: 147-149.

34. Korupolu R, Gifford J, Needham DM. Early mobilization of critically ill patients: reducing neuromuscular complications after intensive care. Contemp Crit Care 2009; 6: 1-12.

35. Bailey P, Thomsen GE, Spuhler VJ, et al. Early activity is feasible and safe in respiratory failure patients. Crit Care Med 2007; 35: 139-145

36. Christopher KL. Transtracheal oxygen catheters. Clin Chest Med 2003; 24: 489-510 